\title{
¿Especies naturalizadas o antropizadas? Apropiación local y la construcción de saberes sobre los frutales introducidos en época histórica en el norte de Argentina*
}

\author{
Naturalized or anthropized species? \\ The local appropriation and construction of wisdoms about \\ introduced fruit trees in historic times in Northern Argentina
}

\author{
Norma I. Hilgert ${ }^{1}$, D. Alejandra Lambaré2 Nilda Dora Vignale $^{2}$, \\ Pablo C. Stampella ${ }^{3}$, María Lelia Pochettino ${ }^{3}$
}

\begin{abstract}
Resumen
Las especies introducidas generalmente son vistas como elementos disruptivos de una naturaleza prístina idealizada. Sin embargo, a través del estudio de las percepciones y prácticas locales en torno a frutales de origen eurasiático en distintos enclaves de Argentina (NOA y NEA respectivamente) se observa que las mismas son elementos constitutivos de ese estado considerado original. Mediante la metodología etnobotánica se relevaron las etnoespecies presentes, prácticas y saberes asociados con representantes del género Prunus en el noroeste y Citrus en el nordeste de Argentina. El análisis etnohistórico permitió identificar las especies introducidas y rutas de acceso, en tanto que la metodología ecológica fue útil para estudiar las poblaciones espontáneas de estos frutales. Se han identificado 9 etnoespecies (divididas en dos grupos de etnovariedades) de duraznos y 8 etnoespecies (que incluyen 27 etnovariedades) de cítricos presentes en las áreas mencionadas, las cuales son expresivas de la diversidad biocultural local. Los ejemplos planteados permiten inferir que estas especies se han incorporado en la visión local como propias y que a través de procesos locales de selección cultural han resultado en poblaciones de especies útiles que conforman un paisaje típico de las zonas de estudio, como resultado de la domesticación del ambiente incluso en un plazo corto como el que representan estos frutales introducidos a partir de la colonización española.
\end{abstract}

Palabras clave: Citrus L., Diversidad biocultural, Domesticación del paisaje, Etnohistoria, Prunus persica, Selección cultural.

\begin{abstract}
Introduced species are generally seen as disruptive elements of an idealized pristine nature. Nevertheless, through the study of local perceptions and practices on fruit trees of Euro-Asian origin in different sites of Argentina (Northwestern and Northeastern respectively), it is observed that they are constitutive elements of the status considered original. By means of ethnobotanical methodology the recognized ethnospecies have been recorded, as well as the knowledge and practices associated with representatives of genus Prunus in Northewestern and Citrus in Northeastern Argentina. The analysis of ethnohistorical sources allowed us to identify the introduced species along with the routes of access, while the methodology of ethnoecology was useful to study spontaneous populations of these fruit trees. Nine ethnospecies (including two groups of ethnovarieties) of peaches and 8 ethnospecies
\end{abstract}

* Este trabajo se presentó en el Simposio Aproximaciones temporales en la interrelación entre seres humanos y plantas del III Congreso Latinoamericano de Etnobiología, realizado en la ciudad de La Paz, Bolivia, en el año 2012, y constituye una síntesis de las investigaciones que vienen desarrollándose en distintas regiones de Argentina, cuyos resultados parciales han sido publicados de forma aislada.

1 Instituto de Biología Subtropical, CONICET, Facultad de Ciencias Forestales, Universidad Nacional de Misiones, Puerto Iguazú, Argentina. e-mail: normahilgert@yaho.com.ar

2 Laboratorio de Botánica Sistemática y Etnobotánica, Facultad de Ciencias Agrarias, Universidad Nacional de Jujuy, Jujuy, Argentina.

3 Laboratorio de Etnobotánica y Botánica Aplicada, Facultad de Ciencias Naturales y Museo, Universidad Nacional de La Plata, La Plata, Argentina.

Fecha recepción: Septiembre 26, 2013

Fecha aprobación: Febrero 22, 2014 Editor asociado: Quinto H

(C) Rev. Biodivers. Neotrop. 2014; 4 (2): 69-87 
(including 27 ethnovarieties) of Citrus have been identified that can be found in the mentioned areas and are expressive of local biocultural diversity. These cases allowed us to infer that these species have been appropriated from local vision, and by means of processes of cultural selection have given rise to populations of useful plants, that form a typical landscape of the studied areas as a consequence of environment domestication, even in the short time, as the one that represent the fruit trees introduced since European conquest.

Keywords: Biocultural diversity, Cultural selection, Citrus L., Ethnohistory, Landscape domestication, Prunus persica.

\section{Introducción}

Los grupos nativos diversos en cuanto a estrategia de subsistencia y establecimiento que desde tiempos pre-hispánicos habitan los distintos enclaves ecológicos de Argentina, construyeron cosmovisiones particulares que acompañaron prácticas de manejo y uso de los recursos vegetales que definían el paisaje local como un espacio dinámico donde se manifestaban significados y valoraciones propias de cada pueblo (Capparelli et al. 2011, Ochoa y Ladio 2011).

A partir del proceso de asentamiento y población europea en América, como fueron las reducciones Jesuitas y las diversas fundaciones colonizadoras en el territorio argentino, estos paisajes culturales cambiaron, al igual que los modos de vida característicos de estos grupos humanos. Es así que se produjo la desestructuración de los espacios nativos y la instauración forzada de un nuevo régimen de explotación y producción, el cual implicó la introducción de objetos y productos del Viejo Mundo, como el ganado y algunos cultivos, que modificaron la conformación y representación del paisaje (Capparelli y Raffino 1997, Giovanetti 2005, Giovanetti y Lema 2005, Lema 2009, Capparelli et al.2011).

El establecimiento de colonias españolas en América, supuso el inicio de un intercambio de especies vegetales entre ambos continentes que afectaría múltiples aspectos de la realidad cotidiana de estos continentes. Pocas veces los estudios atendieron los cambios que se produjeron a partir de 1492, si consideramos las particularidades de cada grupo cultural, en el terreno de la agricultura, la alimentación e incluso en los hábitos o costumbres locales como la medicina, los rituales y celebraciones religiosas. Son numerosos los ejemplos que hacen referencia a la expansión de los vegetales desde épocas muy anteriores a la llegada de las oleadas españolas hacia América y ponen de manifiesto situaciones semejantes para otras zonas del mundo, en particular desde Oriente o el sur (África) hacia el Mediterráneo clásico. Entre ellos se puede mencionar, la caña de azúcar (Saccharum officinarum L.); el avance del Imperio Islámico provocó su instauración en poco tiempo en el sur de Europa. Asimismo, el contacto europeo con África, a mediados del siglo XV, en parte es promovido por el deseo de adquirir especias. La ruta de la seda establecida en los siglos I y II, constituyó una vía comercial de importancia para el intercambio de especias cultivadas. Muchas de ellas llegaron a América como parte constitutiva de la cultura e idiosincrasia del pueblo Ibérico. Entre este elenco de especies se puede mencionar el trigo (varias especies de Triticum), la cebada (Hordeum vulgare L.) y el centeno (Secale cereale [L.] M. Bieb.), habas (Vicia faba L.) y otras leguminosas, frutales de los géneros Prunus, Cydonia, Malus y Pyrus (ciruelas, duraznos, membrillos, manzanas y peras, respectivamente), y otros, junto con especies aromáticas y flores, que se incorporaron como elementos foráneos en el seno de las comunidades (Sepp 1971: 132, García Paris 1991, Giovannetti 2005).

Embarcaciones de todo tipo constantemente intercambiaban germoplasma vegetal entre ambos Mundos y además de semillas, frutos y plantas adultas, era común el transporte de «ramas, retoños, varetas y mugrones (ingertos) de algunos árboles (...)» en toneles para vino (Puente y Olea 1900: 386, 393). El destino principal de estos viajes fueron Las Antillas y posteriormente el continente («tierra firme»), México y Perú, (siglo XVI) para luego, según citan las crónicas, seguir diferentes ruta de ingreso e instauración. A esta ruta caribeña-andina pueden añadirse la asunceña-rioplatense y la brasileña, cada una con sus particularidades de relaciones interétnicas, origen del germoplasma introducido y los conocimientos asociados con cada una de las plantas y al manejo de las mismas.

La siguiente contribución pretende, desde el estudio de las percepciones locales, brindar información referida a la diversidad de etnovariedades, prácticas y saberes asociados con el manejo local que se 
realizan en dos enclaves del norte de Argentina. Estos dos casos forman parte de estudios de mayor alcance y reflejan el trabajo realizado por los autores sobre distintos períodos y regiones del subtrópico argentino: a) el de los cítricos, Citrus L., presente en el nordeste (en adelante NEA) y b) el de los duraznos, Prunus persica (L.) Batsch, del noroeste (en adelante NOA) de Argentina. La historia de introducción, apropiación y reconocimiento local permite relacionarlas y definirlas como elementos representativos del paisaje que integran, por lo tanto, se plantea el interrogante ¿Son elementos disruptivos de una naturaleza prístina idealizada? ¿Actualmente se las puede definir como especies naturalizadas o antropizadas? A través del término «naturalizadas» se definen aquellas especies exóticas cuyas poblaciones se desarrollan sin intervención humana y no necesariamente se comportan como invasoras (Richardson et al.2000, Keller et al.2011); en tanto que antropizadas serían aquellas especies naturalizadas cuya distribución abundancia y características morfológicas están ligadas con procesos de selección cultural y manejo humano.

Asimismo, desde aproximaciones etnohistóricas se presenta una descripción, análisis y comparación de las rutas de ingreso de estos cultivos el que permitirá realizar una proyección temporal con los datos históricos e información etnobotánica acerca del uso y diversidad/diversificación de estas especies.

\section{Metodología}

Área de estudio. Región 1. El nordeste argenti- no, el sur de Misiones y los Distritos fitogeográficos de «los campos»y «del Urunday». Los trabajos de campo fueron realizados en dos departamentos: San Ignacio y Concepción de la Sierra, ubicados al sur de la provincia, el primero a orillas del río Paraná y el segundo a pocos kilómetros del Uruguay (Figura 1). Se trata de una zona de transición entre el Distrito de los Campos y el Distrito de las Selvas Mixtas (Cabrera 1976), donde Martínez-Crovetto (1963) delimita el Distrito del Urunday. En esta región las áreas boscosas se extienden en galerías a lo largo de los ríos Paraná y Uruguay, siguiendo el curso de los arroyos más importantes y cubriendo las laderas de las serranías bajas como Santa Ana, San Juan o San José, definiéndose como una selva empobrecida que avanza sobre las sabanas. También se observan isletas boscosas dentro de una matriz de pastos, conocidas como «capones» (Chebez 2005).

Las poblaciones estudiadas son resultado de la historia de la región. En esta área habitaban diversos grupos que derivaban su economía del «monte» a través de la caza, pesca, recolección y horticultura de Manihot esculenta Crantz, Ipomoea batatas (L.) Lam., Zea mays L., varias especies de Phaseolus y de Cucurbita y otros productos de tierras bajas mediante el sistema de roza y quema (Cadogan 1969, Susnik 1979-1980, Chase Sardi 1989, Schaden 1998). Si atendemos a las descripciones de cronistas y antropólogos, la horticultura y la caza son resaltadas como actividades que proveen la mayor cantidad y variedad de recursos necesarios para la subsistencia de los Mbyá (Bartolomé 1978, Chase Sardi 1989, Schaden 1998). En este sentido, Beate Lehner
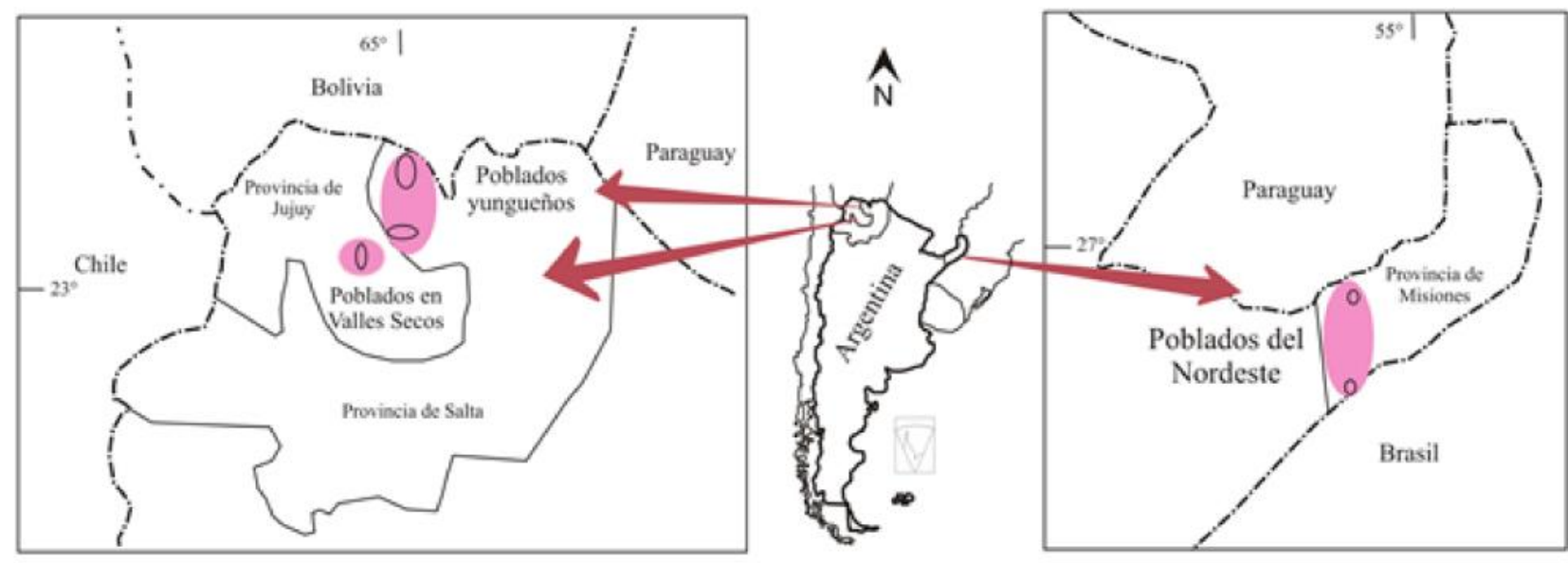

Figura 1. Área de estudio 
(Chase-Sardi 1989: 37) plantea que los «...MbyáGuaraní constituyen una etnia cuya base económica está sustentada, en regular proporción, sobre la horticultura de roza, la caza, la recolección y la pesca, predominando la primera de estas actividades, que con la tercera es fuente de hidratos de carbono, siendo la segunda y en menor medida la cuarta, las que proporcionan proteínas a una rica y bien balanceada alimentación». De esta manera, en la caracterización de los modos de subsistencia de esta etnia, la recolección es subestimada o se le asigna un carácter secundario a la hora de su descripción y análisis (Bartolomé 1978, Chase Sardi 1989, Schaden 1998).

Actualmente se adicionan cultivos introducidos a partir del contacto hispano-indígena como Oryza sativa L., Glycine max (L.) Merr y cría de ganado vacuno, ovino y de animales menores. Las actividades económicas más importantes de la región son la silvicultura y la agricultura, complementada con la ganadería. La primera se basa en las plantaciones de monocultivos de pino (Pinus spp.) y eucalipto (Eucalyptus spp.) para la industria del papel y la madera con sede en la zona, fuente de trabajo de varios pobladores. Los principales cultivos son el tabaco (Nicotiana tabacum L.), yerba mate (Ilex paraguariensis A. St.-Hil.), té (Thea sinensis L.) y las plantaciones de frutales, sobre todo cítricos: mandarinas, naranjas, limones $(C$. reticulata, $C . \times$ aurantium and $C . \times$ latifolia). La economía de la provincia se basa en la extracción de materias primas con poco desarrollo industrial (Schiavoni 1995, 1998).

Las sucesivas oleadas migratorias conformaron comunidades que representan un mosaico de distintas culturas: «criollos», M'byá y descendientes de polacos, ucranianos, italianos, españoles, brasileros, paraguayos, entre otros, siendo las ubicadas en las colonias de Teyú Cuaré y Cerro Mártires, lo más cercanas a «campesinados» (Bartolomé y Schiavoni 2008). Los idiomas hablados son español, guaraní (cuenca del Paraná) y portugués (cuenca del Uruguay). La totalidad de las familias estudiadas en los ámbitos rurales se caracterizan por sistemas productivos tradicionales de subsistencia o venta a pequeña escala en las ferias francas urbanas.

Región 2. El norte argentino: Los valles secos y las Yungas. Se efectuaron trabajos de campo en comunidades campesinas del NOA enclavadas en am- bas laderas de las sierras precodilleranas. En la occidental, en valles intermontanos de las localidades de Juella y Yacoraite, en la Quebrada de Humahuaca (provincia de Jujuy) y en la oriental en dos áreas de la provincia de Salta, en el Valle de Los Toldos (en el departamento Santa Victoria) y en los poblados de la antigua Finca San Andrés (en el departamento de Orán) (Figura 1).

Los valles intermontanos occidentales se corresponden fitogeográficamente con la provincia Prepuñena o Provincia Boliviano-Tucumana caracterizada por la presencia de una vegetación xerofítica y los orientales pertenecen a las Yungas o bosques nublados, caracterizados por la presencia de lluvias orográficas que definen una vegetación exuberante, la que varía a medida que se asciende, reconociéndose tres ambientes: las selvas de transición, selvas montanas y bosques montanos (Cabrera 1976, Navarro y Maldonado 2002).

Si bien hay diferencias definidas por las características de la vegetación y tipo de ambiente, en ambas regiones se desarrollan prácticas agrícolas, destinadas tanto al consumo familiar como para la venta en ferias y mercados regionales. Esta estrategia de subsistencia tiene una larga historia en la zona, y los productos cultivados hasta la llegada de los europeos eran los propios del área andina meridional, donde a la tríada americana (Zea mays-Phaseolus spp. Cucurbita spp.) se agregaban cultivos locales como Chenopodium quinoa Willd., Solanum tuberosum L. y otras especies de papas andinas, Oxalis tuberosa Molina, Ullucus tuberosus Caldas, entre otros, propias del área andina meridional (Karasik 1984, Scarpa y Arenas 1996, Hilgert y Gil 2005).

Habitan estos parajes comunidades descendientes de esta población nativa, pero con algún grado de mestizaje con los europeos arribados a la zona en diferentes momentos. Se habla un español regional, aunque persisten algunas palabras y estructuras gramaticales propias del quechua y aymara (Torres et al. 1985, Albeck 1994, Troncoso 2003, Raffino et al. 2006).

Al estudiar las sociedades agrícolas es importante tener en cuenta las relaciones que establecieron estas con el paisaje, el uso del suelo y los patrones de asentamiento que fueron cambiando a lo largo de la historia. En el NOA, desde el Formativo (2500 AP900 AD) se produce la organización y generación de 
un espacio destinado al manejo agrícola, encauzamiento de los cursos de agua, presencia de muros de contención para protección del suelo. Para el período de Desarrollo Regional (900 AD-1471 AD) se produce la localización definitiva de las sociedades agro-pastoriles en fondos de valles y asentamientos semiurbanos (pukaras), la especialización y el aumento de la arquitectura agrícola vinculada al riego, a la construcción de canchones y terrazas de cultivo, así como el manejo centralizado de sus productos. La anexión del espacio centro andino al imperio incaico produjo cambios en la organización política, económica y social, al igual que más tarde el período de conquista y colonización hispánica. El interés del poder, en este caso, estuvo orientado a la extracción de minerales y a la instalación de áreas de producción agrícola. A ellos debe agregarse la complementariedad, la movilidad interregional de recursos económicos, especies y manufacturas exóticas siguiendo rutas de tráfico adecuada (Albeck 1994, Capparelli et al.2011, Lema 2009, Raffino 1999).

\section{Métodos}

Este estudio se basa en investigaciones etnobotánicas desarrolladas en diferentes momentos con el fin de identificar formas de manejo y riqueza de la agrobiodiversidad en cada enclave definido en el área de estudio. En yungas se realizaron los muestreos entre 1994 y 2000 , en los valles secos y el nordeste se iniciaron los trabajos en el 2010 y continúan en el presente. En estos dos casos se trabaja con especies y variedades del género Prunus y Citrus, respectivamente. Se implementaron técnicas cualitativas. Los primeros pobladores que participaron del trabajo fueron seleccionados al azar y en algunos casos posteriormente se procedió mediante bola de nieve, es decir, se incluyeron a nuevos informantes a partir de recomendaciones de los primeros y así sucesivamente (Bernard 2000, Albuquerque et al . 2010). En el NOA, en las yungas se trabajó con un total de 59 personas, en los valles secos con 26 y en el NEA con 36 . Las entrevistas realizadas a cada una de las personas fueron orientadas a indagar acerca del conocimiento local sobre los nombres comunes con los que son reconocidas las especies, las partes útiles y los usos asignados.
Mediante la revisión de 39 fuentes bibliográficas y de documentación histórica de distintas disciplinas, abarcando el período de 1500 hasta la actualidad, se obtuvo información referida al ingreso de estos cultivos en América. Se trabajó con documentación histórica de diversa índole, diferencialmente de acuerdo al enclave considerado teniendo en cuenta la historia local de cada uno y la disponibilidad de fuentes: cronistas e historiadores de Indias, historiadores naturales y religiosos jesuitas, libros de viajeros, obras de botánicos e información arqueobotánica, etnobotánica e histórica (Hernández Bermejo y Lora González 1996). Las fuentes consultadas fueron: Acosta 1590, Ferrari 1646, Commelyn 1683, Volkamer 1708-1714, Azara 1847, Casas 1875, Lista 1883, Holmberg 1887, Burmeister 1899, Cobo 1890-1892 [1580-1657], Gambón 1904, Lizárraga 2002 [1607?], López de Gómara 1922 [1552], Schmidl 1944, Cabeza de Vaca 1947 [1490-1558], Vázquez de Espinosa 1948 [1630], Díaz de Guzmán 2000 [1602] y Ambrosetti 2008a, b [1892, 1896, 1898]. Para el período colonial en NEA se consultaron, además, obras de los Jesuitas publicadas entre los siglos XVII y XVIII (Ruíz de Montoya 1892 [1639], Sánchez Labrador 1910 [1770], Paucke 1944 [1749-1767], Dobrizhoffer 1967 [1784], Sepp 1971 [1696], Cardiel 1994 [1771]). Para contextualizar el período estudiado en NOA y NEA se consultaron publicaciones y tesis de historia, etnohistoria y botánica histórica: Brabo (1872), Puente y Olea (1900), Levillier (1939), Báez (1947, 1949), Susnik (1979-1980), Mörner (1985), Carbonell (1992), Ramón-Laca (2003), Capparelli et al. (2005), Giovanetti (2005), Sica (2005), Vitri (2007), Gentille Lafaille (2012). El trabajo de Puente y Olea (1900) referido a los trabajos geográficos de la Casa de la Contratación, permitió contextualizar el proceso de ingreso de estos frutales, ya que presenta una descripción de lo que ocurría en el continente Americano en el momento del ingreso de la población colonial.

Las muestras botánicas resultado del trabajo de campo realizado en cada zona de estudio se identificaron y depositaron en el Herbario de Plantas Útiles y en la Colección de Frutos y Semillas del Laboratorio de Etnobotánica y Botánica Aplicada de la Facultad de Ciencias Naturales y Museo, Universidad Nacional de La Plata, con la asignación de siglas y número de registro personal de los autores. 


\section{Resultados y discusión}

Historia de ingreso y uso de especies de Citrus en el NEA. Los cítricos son originarios del este, sur y sudeste Asiático, Australia y Sudoeste de las islas del Pacífico (Zhang y Mabberley 2008). Exceptuando el cidro (Citrus medica L.) que ya era conocido por los griegos y romanos y la naranja dulce, mandarina y pomelo, de introducción posterior, la mayoría de los cítricos ingresan a Europa siguiendo las rutas conquistadoras de los musulmanes durante los siglos X y XI (Ramón-Laca 2003). Son llevados a América durante el segundo viaje de Cristóbal Colón en 1493. Los escritores de la época citan pepitas y simientes de naranjas, limones y cidras además de melones $y$ de toda hortaliza (Casas 1875, II, LXXXIII: 3) llevados a Centroamérica desde la Isla de la Gomera (perteneciente al grupo de las Canarias). Estas referencias corresponderían respectivamente a Citrus $x$ aurantium L., Citrus $\times$ limon, Citrus medica L. y Cucumis melo L. A estas «especies», Puente y Olea (1900) agrega toronjas y limas que corresponderían a Citrus maxima (Burm.) Merr. y al grupo de Citrus $\times$ aurantiifolia (Christm.) Swingle y Citrus $\times$ limettioides Tanaka. También destaca que las primeras rutas de ingreso de plantas cultivadas fueron Andalucía y Castilla (en España), Guinea (África) y del Asia como «ciertos naranjos de fruta grande, llevados desde Filipinas» (1900: 375). Hacia el último cuarto del siglo XVI algunos representantes del género Citrus L., como las naranjas y los limones, ya se encuentran naturalizados en América. El Padre José de Acosta (que llega a Perú en 1572) comenta que los cítricos son los árboles que más se han multiplicado y con mayor abundancia y se asombra ante la conformación de «bosques de naranjos», nombrando también las «limas, cidra y fruta de este linage»

La facilidad de naturalización de los cultivares menos domesticados de Citrus, en especial los utilizados como portainjertos, está relacionada con los ambientes donde son cultivados y por las comunidades locales, la abundante fauna que consume sus frutos y por los procesos de hibridación y apogamia que complementan la reproducción sexual (Capparelli et al. 2011). Al parecer el ingreso (así como el egreso) de germoplasma vegetal fue continuo y cuantioso, diversificándose a medida que los diversos enclaves mundiales fueron poniéndose en contacto (Figura 2).
En el período jesuítico, los cítricos eran cultivados en distintos ambientes de las Misiones Guaraníticas, encontrándose las variedades más domesticadas en los jardines de los jesuitas y en los colegios (Capparelli et al.2011). Además, había naranjales (pertenecientes al Tupambae, es decir a aquellos predios de producción comunitaria dedicados a cultivos en gran escala) destinados al consumo y a la venta (Carbonell 1992, Gálvez 1995).

Es posible hipotetizar acerca de cuáles eran los cultivares que crecían en las misiones jesuíticas tomando como referencia las obras de los jesuitas Paucke (1944) y Sepp (1971) y a los inventarios de la expulsión de los jesuitas de Brabo (1872). Entre ellos se hallan los limones (agrios), limones dulces, limones ceutíes, limas dulces, cidros, toronjas, naranjos dulces y agrios, naranjos de cáscara fina y naranja de la China. Las variedades selectas con frecuencia eran cultivadas en los huertos y jardines de los jesuitas (a los cuales sólo tenían acceso los Padres y pocos guaraníes horticultores) y en los colegios de Buenos Aires, Córdoba, Santa Fe y Asunción. Los cultivares «comunes» 0 «vulgares» se hallaban cultivados en el Tupambae y en ocasiones en algún Abambae (predios asignados a cada familia para la producción de autoconsumo), además de las variedades «silvestres» seguramente naturalizadas en los bosques más o menos modificados por el manejo agroforestal intenso.

Con el extrañamiento de la orden religiosa en 1768 las misiones son abandonadas y durante los años posteriores, ocurrieron múltiples migraciones a los montes vecinos, a Corrientes, Santa Fe, Buenos Aires y Asunción, entre otros (Gálvez 1995). Los cultivos abandonados entraron en un proceso de regeneración forestal en varios parches antes cultivados. Es de esperar que los más cercanos a las construcciones -algunas aún habitadas por pocos años más, a pesar de las invasiones portuguesas y paraguayas de 1817 y 1818 - fueran sometidos a manejo de la cobertura arbórea superior, como también de los «montes frutales», yerbales y algodonales abandonados. Los naranjales son recordados por los pobladores entrevistados hasta hace pocos años atrás y observados $\mathrm{y}$ elogiados por los viajeros de Misiones de fines de siglo XIX y principios del XX [Lista 1883, Holmberg 1887, Gambón 1904, Ambrosetti 2008 $(1892,1896)]$. 


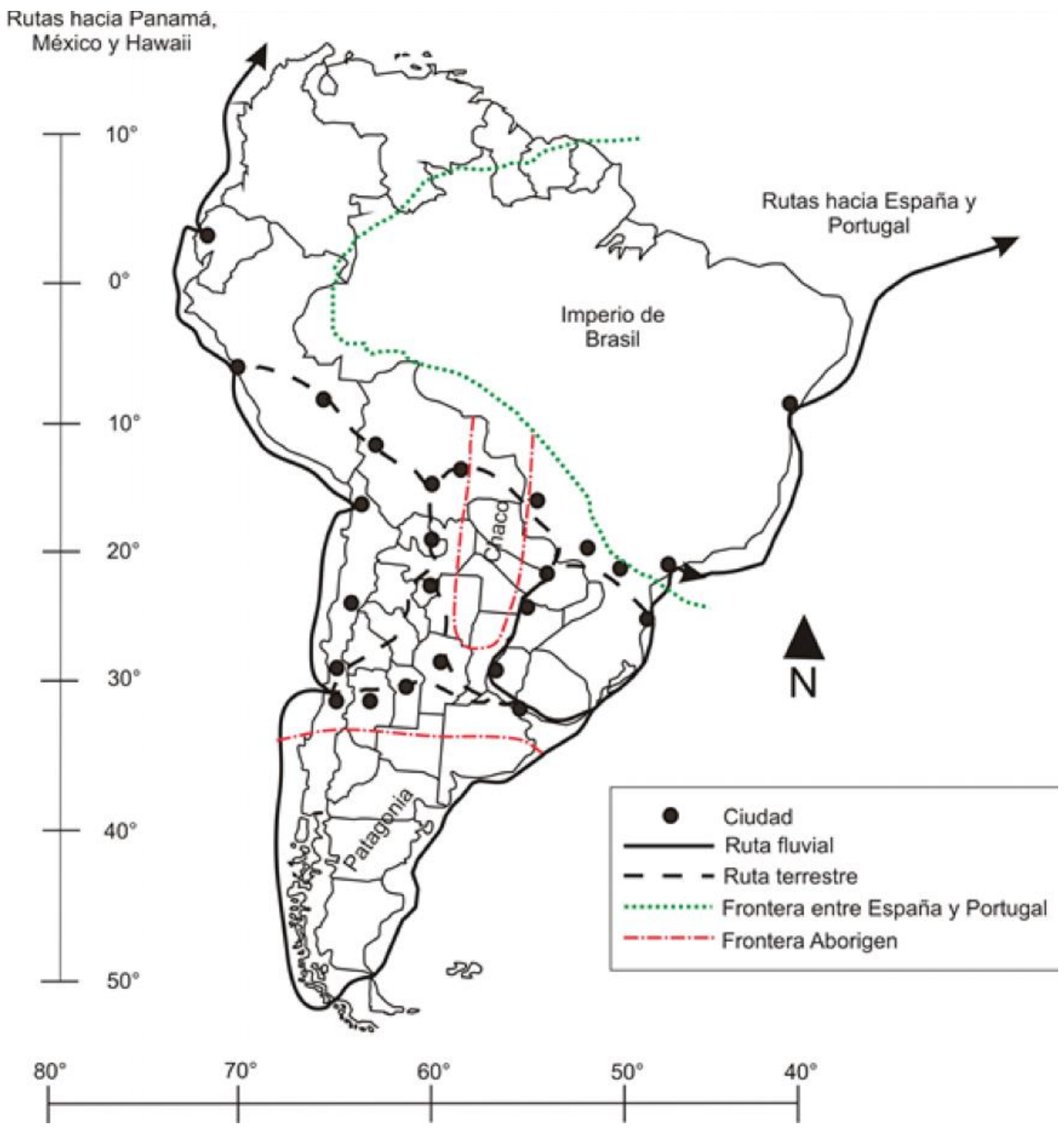

Figura 2. Rutas del siglo XVI

Historia de ingreso y uso del cultivo de duraznos en el NOA. Prunus persica (L.) Batsch (Prunoideae) es una especie perteneciente a la familia Rosaceae. El registro bibliográfico establece su origen en las zonas montañosas del Tíbet y del suroeste de China. Su presencia en el Mediterráneo remonta a comienzos de la Era Cristiana, sin embargo, su taxonomía e historia de evolución actualmente siguen siendo poco claras en cuanto a centros de origen y de dispersión (Depypere et al. 2007, Burger et al.2011).

Fue para el siglo XVI, que los primeros navíos y galones provenientes de Sevilla llegaron a las Antillas, trayendo entre otras especies vegetales los frutales «de Castillas» o «de hueso» entre los que se hace referencia a los «duraznos». Luego, es en México y Perú (principalmente Lima) donde este germoplasma ingresa, siendo una de las vías seguidas para dispersarse por el resto del continente (Puente y Olea 1900).

Para el caso de las comunidades presentes en el noroeste de Argentina, los registros permiten postular que los duraznos ingresaron a Jujuy a la zona de los valles secos en el período colonial, desde rutas 
provenientes del Perú. Si bien en la bibliografía existe evidencia que demuestra que podrían haber sido introducidos por Chile (Báez 1947, 1949, Capparelli et al.2005), resulta lógico -y basado en el relato escrito (Sica 2010)- suponer que la relación entre la zona andina en Argentina fue más estrecha con Perú que con Chile, aún cuando la provincia de Jujuy era integrante de la gobernación del Tucumán. Esta relación puede entenderse principalmente producto de la ubicación geográfica, propicia para el intercambio y la comercialización (Farberman y Boixadós 2006) (Figura 2).

El primero en recorrer los caminos de la región del noroeste en Argentina es Diego de Almagro. En el año 1535 emprende su recorrido por el antiguo camino Inka Kollasuyo, hacia el sur con el objetivo de buscar metales preciosos y tierras aptas para el cultivo; su recorrido llega hasta el valle de Copiapó (Chile). Luego de cuatro meses de viaje llega a Tupiza, a $80 \mathrm{~km}$ del límite boliviano-argentino. Ingresa a este territorio en el año 1536; los datos de las rutas de Almagro son extraídos de la «Carta ASM del Oidor de los Charcas, Licenciado Juan de Matienzo» de fecha 2 de enero de 1566. Durante todo el viaje fue enviando adelantados para que reconozcan el camino más seguro y mejor aprovisionado de pasturas y agua para los animales y lugares poblados donde pudieran obtener alimentos para el ejército (Vitri 2007). Ningún cultivo del Viejo Mundo fue consumido durante esta expedición (Capparelli et al. 2005).

Diego de Rojas realiza en 1543 otra expedición y toma los conocimientos que Diego de Almagro adquirió tras su paso por la región. Posteriormente a estas expediciones, los españoles, asentados por un lado en Perú y por otro en Chile, compitieron y lucharon entre ellos y con los aborígenes locales para dominar el noroeste. En 1549 las autoridades del Perú ordenan a Juan Núñez de Prado que realice el mismo viaje con el mandato concreto de fundar un pueblo en Tucumán (Levillier 1939). La primera fundación que tuvo lugar en el actual territorio de noroeste de Argentina (actual cuidad de Tucumán), fue Barco de Ybatín fundada en 1550. Cabría esperar teniendo en cuenta que este resulta ser el primer asentamiento español en el NOA, que los hombres que realizaron este viaje llevaron elementos mínimos para la subsistencia, como ganado y especies vegetales, principalmente trigo y cebada (Giovanetti 2005). Producto de este período se fundaron tres villas: 1. Barco (1550 AD) en la moderna provincia de Tucumán; 2. Santiago del Estero (1553) en la moderna provincia homónima; 3. Londres de Quimivil (1558) en la moderna provincia de Catamarca. La primera fue fundada por Núñez del Prado, un español que venía de Perú, y las dos últimas por españoles que venían de Chile: Francisco de Aguirre y Juan Pérez de Zurita respectivamente (Capparelli et al. 2005).

Según los registros entre la segunda mitad del siglo XVI y el comienzo del XVII, si bien estos cultivos españoles no formaban parte de lo que los nativos consumían cotidianamente, ya se encontraban en proceso de manipulación e incorporación (Báez 1947, 1949; Giovanetti y Lema 2005). En efecto, hay evidencias arqueológicas del empleo comestible y ceremonial de los duraznos en contextos rituales por poblaciones nativas del período Hispano-Indígena alrededor del 1600 (Capparelli et al.2005). Posiblemente llegaron a manos de poblaciones nativas, ya sea por que fueran robadas o abandonadas en expediciones frustradas (Sica et al. 2010). A finales del siglo XVII el sistema colonial en la región del Tucumán estaba definitivamente consolidado. Las antiguas sociedades prehispánicas se habían transformado en «indígenas» coloniales, y la mayor parte de ellos vivía bajo el régimen de encomienda (Sica 2010). Lizárraga (2002) retrata a las nuevas ciudades de la Argentina y al llegar a la provincia de Mendoza en el siglo XVI, expresa: «La cibdad es fresquísima, donde se dan todas las frutas nuestras, árboles y viñas, y sacan muy buen vino que llevan a Tucumán o de allá se lo vienen a comprar».

La instalación española en esta región estuvo ligada a la capacidad de los conquistadores de hacer producir las tierras con mano de obra indígena a partir de las demandas de un naciente mercado altoperuano con centro en Potosí, con el descubrimiento y explotación de la mina descubierta en 1554. Tras la conquista, los mayores cambios del paisaje agrario de la quebrada de Humahuaca se realizaron en el antiguo espacio de cultivos mesotérmicos. Se abandonaron los grandes sitios agrícolas situados en zonas de altura, para concentrarse en los fondos de valle. En estas franjas menos empinadas y más planas se adaptaron los nuevos cultígenos (sobre todo, cereales como el trigo, cebada y frutales) (Sica 2010).

Sica (2005), transcribe el relato de Sotelo de 
Narváez en los valles Calchaquíes en 1580, antes de la fundación definitiva de Jujuy:

«...hay muchas crías de yegua, vacas, mulas, ovejas y cabras y puercos en abundancia; de todo lo cual tienen los indios y los crían como españoles... Cogese en esta tierra trigo y maíz, cebada y mucha cantidad de frisoles y dasé todo lo de Castilla, por la experiencia que se tiene de haber estado en esta tierra poblado un pueblo de españoles».

Asimismo en referencia al mismo documento (Relación de las provincias del Tucumán por Pedro Sotelo de Narváez, publicado por Gentile Lafaille (2012: 599) aparecen referencias de estos cultivos:

«Los Españoles y Ellos tienen agora frutas despaña que se an plantado viñas de que se cojen munchas vuas y vino. durasnos higos melones menbrillos y mançanas granadas. perales y çiruelos avn no an dado fruta ay limas y naranjas».

En 1590 se produce un proceso de internalización de la circulación comercial, se constituye un comercio integrado desde Potosí a Buenos Aires vía Tucumán; de este modo queda relegada la anterior dependencia que la región del NOA tenía con Chile (Palomeque 2000). En ese contexto, Jujuy durante la época colonial fue considerada como zona de paso y frontera con el Tawantisuyo, era empleada tanto por la población nativa como por los españoles como ruta para llegar a Bolivia (Potosí) y a Perú (Lorandi 1988).

Apropiación y situación actual de los frutales introducidos. Las introducciones intencionales, los procesos naturales de diversificación (hibridación, poliploidía, agamospermia) y los procesos culturales de selección de la diversidad son algunos de los procesos que resultan en la diversidad actual de frutales exóticos (Capparelli et al. 2011). A estos deben agregarse las introducciones no intencionales, como es el caso de los porta-injertos de cultivares de Citrus y Prunus (Lambaré y Pochettino 2012, Stampella et al. 2013a). Sin embargo, desde el marco teórico de la Ecología Histórica, que plantea la intervención humana (sino total) en espacio y tiempo (Balée 1998), el control antrópico también reviste importancia so- bre los procesos naturales de diversificación. Desde esta perspectiva, las recombinaciones híbridas originadas naturalmente, son favorecidas mediante la «hibridación del hábitat»-término propuesto a principios de 1970 por Grant (1989). Esta diversificación del paisaje está íntimamente relacionada con la diversidad cultural y de prácticas sobre el entorno. Por lo tanto, hay una selección cultural de determinados fenotipos en base a caracteres deseados, la eliminación de fenotipos indeseados (como el «apepú» en los ámbitos urbanos o en los «potreros») y una perpetuación de fenotipos híbridos, dada la provisión de un continuum de hábitats potenciales para su formación y establecimiento.

El caso de los Citrus. Los ambientes relevados en la actualidad en el NEA son huerto y ámbito peridoméstico, campo, monte, capuera y rozado (Stampella et al. 2013b). A esta diversidad de ambientes se agrega una diversidad de prácticas de manejo sobre los mismos, dada por el mosaico cultural de la provincia. Asimismo, la transición entre estos ambientes es también diversa; en algunos casos se han observados interfases difusas entre monte y campo, mientras que la presencia de alambrados y «empaladas» determina límites más fijos, por lo menos en el caso de la movilidad del ganado.

Durante el siglo XVIII las misiones jesuíticas adquieren la conformación final de sus reducciones. Los ambientes productivos definidos en base a la presencia de frutales fueron el arbolado urbano y los jardines, el cementerio, el huerto de los padres jesuitas, el Abambae de cada familia guaraní y la gran diversidad de Tupambae comunales, que incluían «huertos frutales» (naranjales, duraznales), «yerbales», «algodonales» y cultivos de caña de azúcar y tabaco (Paucke 1944, Capparelli et al. 2011).

El arbolado urbano estaba conformado de varias especies frutales, entre ellas cítricos (naranjos y limoneros), duraznos e higueras (Cardiel 1994, Gálvez 1995). En el cementerio de las misiones siempre estaban presentes especies vegetales con aromas dulces, como los naranjos (azahares) y los narcisos (Narcissus) (Gálvez 1995). Pero entre los ambientes domésticos es el huerto de los jesuitas el que alcanza mayor complejidad y diversidad. Las fuentes históricas documentan la presencia de especies herbáceas, arbustivas y arbóreas, nativas y exóticas, cultivadas con fines ornamentales, medicinales y ali- 
menticios, entre otros. Este espacio también era destinado a la aclimatación de las especies introducidas y, quizás, a la experimentación ya que se trataba de un espacio vedado a la mayoría de los guaraníes. Desde los huertos se dispersaron las primeras plantas introducidas y los porta-injertos destinados a soportar los esquejes seleccionados. Según la literatura, la diversidad de etnovariedades en estas parcelas superaba a la de los otros ambientes; esto pudo ser así, o quizás solo sea efecto de la importancia de las mismas. Se citan 8 variedades de duraznos y 12 de cítricos, además de otras especies frutales y útiles (Sepp 1971, Paucke 1944, Brabo 1872).

Es muy probable que la naturalización de varias especies de frutales haya sido instantánea, o por lo menos en lo que respecta a variedades menos domesticadas, denominadas «comunes», «silvestres», «ordinarios» $\mathrm{o}$ «vulgares» en los tratados de cítricos de Ferrari (1646), Commelyn (1683) y Volkamer (1708-1714). Las primeras expediciones ya traían consigo semillas, plántulas en barriles, estacas e injertos (Stampella et al.2013b) para ser plantadas en los jardines de las islas del Caribe. En las obras de los cronistas tempranos -siglos XVI y XVII- ya aparecen referencias acerca del escape de cultivo de estos frutales. El Padre José de Acosta (que llega a Perú en 1572), extrañado ante el comportamiento de los cítricos en el Nuevo Mundo, se asombra ante la abundancia en campos y bosques:

«De árboles, los que mas generalmente se han dado allá, y con mas abundancia, son naranjos, limas, cidras y fruta de este linage. Hay ya en algunas partes montañas y bosques de naranjales, lo qual haciendome maravilla, pregunté en una Isla, ¿quien había llenado los campos de tanto naranjo? Respondieronme, que acaso se había hecho porque cayéndose algunas naranjas, y pudriéndose la fruta, habían brotado de su simiente, y de la que de estos y de otros llevaban las aguas á diversas partes, se venían á hacer aquellos bosques espesos: parecióme buena razón» (Acosta 1590, I, XXXI: 261).

Durante el siglo siguiente, el jesuita Bernabé Cobo, señala la afinidad de estos frutales con América incluso en «lugares desiertos e incultos», refiriéndose seguramente a distintos ambientes boscosos. Es uno de los primeros cronistas que destaca el origen doméstico de los frutales silvestres:

«...parece haber estado todas estas plantas (los cítricos) en las demás regiones del mundo como desterradas y fuera de su naturaleza, hasta que llegaron á esta tierra; la cual les es tan natural, que ninguna otra planta, así de las propias y naturales de acá como de las extranjeras y peregrinas, abraza mejor y conserva más tenazmente. Lo cual, cuánta verdad tenga testifican las grandes montañas y bosques que se han hecho en estas Indias de Naranjos, Limones y de los demás árboles deste género, naciendo en lugares desiertos é incultos, como si fueran plantas silvestres las que de suyo son tan domésticas y hortenses, que se plantan y cultivan en todo el mundo con gran diligencia y regalo» (Cobo 1890, VIII, XXI: 396).

Azara (1847), en su paso por las Misiones recientemente abandonadas luego del extrañamiento de los Jesuitas nota los «bosques de naranjos casi puros cercanos a los pueblos o dónde los ha habido», juzgando que se «agriaron por falta de cultivo». Puente y Olea (1900: 388) dispara una frase que puede servirnos de base en este trabajo: la reproducción en las condiciones naturales de que habla el P Acosta conduce, en efecto, y rápidamente, á variedades silvestres. Este autor lo contrasta con lo que pasa en Andalucía, donde ocurre lo mismo pero aunque no se utilice porque además de la lentitud, el naranjo resulta generalmente basto, agrio, ó agridulce, y en general exige el injerto. Esto puede relacionarse con los relevamientos etnobotánicos actuales en la zona donde se diferencian las variedades «caseras» y las «del monte», como pertenecientes a los grupos denominados «injertadas»y «comunes, respectivamente».

Hacia finales del siglo XIX, Burmeister (1899: 11-12) cita «naranjos mandarinos» (Citrus reticulata Blanco) para la provincia de Corrientes, recomendándolos junto con los «naranjos comunes»y al «chirimoyo» (Annona cherimola Mill.) en cultivos intensivos para la exportación a grandes ciudades. Poco antes fueron incorporados por Hieronymus (1882) en su obra bajo la denominación de «naranjo fino» o «mandarino» (Citrus deliciosa Tenore) re- 
portando sus usos idénticos a los del naranjo dulce (antiescorbútica, béquica [tos] y contra enfermedades de la bilis). Los «pomelos» 0 «grapefruit» (Citrus $x$ aurantium $\mathrm{L}$.) ingresan posiblemente junto con la mandarina o quizá poco antes. Su origen es discutido, si mutación o hibridación, aunque se acepta Barbados como lugar geográfico, hacia principios del siglo XVIII, dispersándose hacia otras islas recién poco menos de un siglo después (Kumamoto et al. 1987; Citrus Pages 2013). Posiblemente fueran confundidos con «pampelmusas»o «toronjas» (C. maxima). En la actualidad persisten las evidencias de la naturalización de los cítricos en diversos enclaves del país, sobre todo aquellos pertenecientes al dominio subtropical con varios taxa como Citrus $\times$ aurantium L. (grupo Pomelo y grupo Naranja amarga), $C . x$ taitensis Risso, $C$. trifoliata L. y C.reticulata Blanco (Seo y Xifreda 2008, Hurrell et al. 2010, Stampella et al. 2013a, IBODA 2013).

Las introducciones registradas en la región coinciden con la reconfiguración de las poblaciones locales a través del proceso migratorio que tuvo lugar en los primeros años del siglo XX. Los inmigrantes que llegan a territorio misionero lo hacen en un primer momento con la colonización oficial la cual se inicia en 1898 con el arribo de polacos y ucranianos de la zona de la Galitzia -una de las comarcas más pobres de la Europa campesina- al pueblo de Apóstoles. El Estado también es responsable del poblamiento de las tierras localizadas sobre la dorsal central (Além, Oberá, Cainguás). Por su parte la colonización privada incorpora principalmente inmigrantes alemanes provenientes de Brasil o directamente de Europa y se extiende principalmente por la zona del Alto Paraná. Posteriormente a esta zona arribarán inmigrantes criollos y paraguayos en busca de trabajo (Gallero y Krautstofl 2009). Con estos inmigrantes llegan nuevos saberes y prácticas sobre el entorno, así como valoración diferente de las plantas con las que iban a interactuar; como ejemplo se puede citar que las naranjas que en la nueva tierra eran comunes, en la tierra de origen constituían un regalo, según diferentes relatos, que se recibía por navidad. Otra fuente de variabilidad fue la industrialización de los cultivos. Luego del primer cuarto del siglo XX, con el inicio de la citricultura en el NEA, se diversifican las introducciones de los cultivares de distintos enclaves del mundo (África, India, EE.UU., China, Ja- pón). El modelo de industria citrícola es EE.UU. (Florida y California) cultivándose variedades injertadas principalmente sobre «naranjo amargo», que luego es reemplazado debido a la epidemia del virus de la tristeza, por portainjertos de «naranjo dulce», «naranjo Cleopatra», «lima de Rangpur»y «lima dulce», entre otros (Webber 1943, Palacios 1978). Hacia la década de 1970 se produce una homogeneización de los cultivares debido a la creciente globalización agraria y la demanda del mercado de frutos uniformes en cuanto a tamaño, forma, color y sabor. Actualmente, $78 \%$ de los cítricos cultivados corresponde a «mandarinas» («Satsuma», «Clementina» $\mathrm{y}$ «Murcott»); 17\% a «naranjas» («Valencia Late», «Salustiana», «Lanelate» y «Newhall') y 5\% restante a limones («Tahiti» $\mathrm{y}$ «Eureka») (Compañía Tabacalera de Misiones Ltda. 2013). A pesar de ello, varios cultivares, algunos de ellos naturalizados (Seo y Xifreda 2008, Stampella et al.2013b), son percibidos como frutales autóctonos. El «apepú», la «naranja común», la «mandarina común», la «lima dulce» y el «limón mandarina» son considerados «del monte». Si bien hay discrepancias entre los informantes con respecto a su naturaleza «autóctona», la mayoría considera casi todos los cultivares anteriores y la totalidad de los informantes a «apepú», reforzado este último por su nombre en guaraní, que significa a: fruta / pe: cáscara / pú: ruido, sonido, ruptura (Storni 1944). Para Cadogan (1957) «apepu» significa fofo, flojo; mientras que sólo «ape» es dorso o superficie, y «pu» sonido hueco, refiriéndose al sonido que hace el epicarpo al ser golpeado con los dedos, característica distintiva de «apepú».

En la zona en estudio, los cítricos presentan una diversidad de usos variable según los grupos culturales a los cuales están asociados. Generalmente, los «criollos» $\mathrm{y}$ «Mbya» emplean las variedades «comunes» -y los últimos algunas variedades «injertadas» adquiridas- como fruta de invierno (naranja, apepú, mandarina, lima), condimenticio (limones), forrajero para el ganado en invernada (variedades «silvestres») y como sombra alrededor de los hogares. Los «colonos», principalmente los «polacos»y «japoneses», emplean las variedades «injertadas» por ellos mismos como frutales y en la producción de conservas (dulces, salsas, frutas «abrillantadas») para consumo o venta en las ferias francas. El «dulce de oreja», elaborado con los mesocarpos de los frutos de apepú, 
aún sigue empleándose -aunque en menor medidacomo postre típico en la zona. Es de destacar la diversidad de usos medicinales en todos los enclaves estudiados relacionados al tratamiento de distintas dolencias, principalmente digestivas, respiratorias y generales (contra fiebres, gripes, hipertensión arterial, y como refrescante) siendo las variedades más empleadas «apepú», «limón mandarina», «mandarina» y «naranja».

En el momento actual se encontraron 8 etnoespecies de Citrus (las que incluyen 27 etnovariedades) (para mayores detalles ver Stampella $e t$ $a l$. [2013b]), las que reciben diferentes tipos de ma- nejo) (Tabla 1 y Figura 3).

El caso de los duraznos. La introducción de los frutales de pepita y de carozo de la familia Rosáceas en el NOA resultaron en el establecimiento como cultivos locales, los que se mantuvieron mediante reproducción por semillas o bien vegetativamente, $\sin$ introducción de nuevo germoplasma. Por este motivo son poblaciones constituidas por las mismas variedades introducidas en tiempos de la colonia pero que reflejan los criterios de selección cultural local y la adaptación a un paisaje particular. En el caso de los duraznos, estos 500 años de historia conformaron un grupo de 9 etnoespecies de duraznos, pertene-

Tabla 1. Etnovariedades de cítricos de Misiones discriminando manejo local, estado y espacio donde se encuentran.

\begin{tabular}{|c|c|c|c|c|}
\hline Etnoespecie & Etnovariedad & Manejo local & Estado & Espacio \\
\hline Cidra & Cidra & SS & Cultivado & AP \\
\hline Pomelo & pomelo blanco & $\begin{array}{l}\text { SS, SF } \\
\text { SS SF }\end{array}$ & Cultivado, remanente & $\begin{array}{l}\mathrm{AP}, \mathrm{H}, \mathrm{R}, \mathrm{C}, \mathrm{CP} \\
\mathrm{AP} \mathrm{CP}\end{array}$ \\
\hline \multirow[t]{2}{*}{ Apepú } & $\begin{array}{l}\text { apepú silvestre } \\
\text { apepú casera }\end{array}$ & $\begin{array}{l}\text { CG, MIS, SS, P } \\
\text { SS, P }\end{array}$ & $\begin{array}{l}\text { Espontáneo } \\
\text { Cultivado, remanente, } \\
\text { espontáneo }\end{array}$ & $\begin{array}{l}\mathrm{CP}, \mathrm{C}, \mathrm{M} \\
\mathrm{AP}, \mathrm{H}, \mathrm{C}, \mathrm{CP}\end{array}$ \\
\hline & apepú dulce & DS, CG, MIS, SS, P & Cultivado, remanente & $\mathrm{AP}, \mathrm{H}, \mathrm{C}, \mathrm{CP}, \mathrm{M}$ \\
\hline \multirow[t]{2}{*}{ Naranja } & $\begin{array}{l}\text { naranja silvestre } \\
\text { naranja casera }\end{array}$ & $\begin{array}{l}\text { DS, CG, MIS, SS, P } \\
\text { SS, SF, P }\end{array}$ & $\begin{array}{l}\text { Espontáneo } \\
\text { Cultivado, remanente, } \\
\text { espontáneo }\end{array}$ & $\begin{array}{l}\mathrm{CP}, \mathrm{C}, \mathrm{M} \\
\mathrm{AP}, \mathrm{H}, \mathrm{C}, \mathrm{CP}\end{array}$ \\
\hline & naranjas injertadas & SS, SF & Cultivado & $\mathrm{AP}, \mathrm{H}$ \\
\hline \multirow{4}{*}{ Mandarina } & $\begin{array}{l}\text { mandarina silvestre } \\
\text { mandarina casera }\end{array}$ & $\begin{array}{l}\text { DS, CG, MIS, SS, P } \\
\text { SS, SF, P }\end{array}$ & $\begin{array}{l}\text { Espontáneo } \\
\text { Cultivado, remanente, } \\
\text { espontáneo }\end{array}$ & $\begin{array}{l}C P, C, M \\
A P, H, C, C P\end{array}$ \\
\hline & $\begin{array}{l}\text { mandarinas } \\
\text { injertadas }\end{array}$ & SS, SF & Cultivado & $\mathrm{AP}, \mathrm{H}$ \\
\hline & $\begin{array}{l}\text { mandarina colora- } \\
\text { da o mandarinola }\end{array}$ & SS, SF, CG, MIS & Cultivado, remanente & $\mathrm{AP}, \mathrm{H}, \mathrm{C}, \mathrm{CP}$ \\
\hline & $\begin{array}{l}\text { mandarina colora- } \\
\text { da japonesa }\end{array}$ & SS, SF & Cultivado, remanente & $\mathrm{AP}, \mathrm{H}, \mathrm{C}$ \\
\hline \multirow{5}{*}{ Limón } & $\begin{array}{l}\text { limón o limón } \\
\text { mandarina }\end{array}$ & DS, CG, MIS, SS, P & $\begin{array}{l}\text { Cultivado, remanente, } \\
\text { espontáneo }\end{array}$ & $\mathrm{AP}, \mathrm{H}, \mathrm{R}, \mathrm{C}, \mathrm{CP}, \mathrm{M}$ \\
\hline & limón amarillo & SS, SF & Cultivado & $\mathrm{AP}, \mathrm{H}$ \\
\hline & limón lima & SS & Cultivado & $\mathrm{AP}, \mathrm{H}$ \\
\hline & $\begin{array}{l}\text { limón cidra o limón } \\
\text { rugoso }\end{array}$ & SS, MIS, P & Cultivado, remanente & $\mathrm{AP}, \mathrm{H}, \mathrm{C}, \mathrm{CP}$ \\
\hline & $\begin{array}{l}\text { limon sutil o lima } \\
\text { ácida }\end{array}$ & SF & Cultivado & $A P$ \\
\hline Lima & lima & DS, CG, MIS, SS, P & $\begin{array}{l}\text { Cultivado, remanente, } \\
\text { espontáneo }\end{array}$ & $\mathrm{AP}, \mathrm{H}, \mathrm{C}, \mathrm{CP}, \mathrm{R}, \mathrm{M}$ \\
\hline Quinoto & quinoto & SS, SF & Cultivado & AP \\
\hline Trifoliata & trifoliata & -- & Remanente, espontáneo & $A P$ \\
\hline
\end{tabular}

Manejo local: dispersión in situ de semillas por consumo de frutos en el «monte» (DS), cría de ganado («invernada») en el «monte» (CG), tolerancia de plantas silvestres en ámbitos domésticos y productivos e incluso favorecimiento (prácticas de manejo in situ) (MIS), Selección de semillas para la siembra (SS), Selección de fenotipos (especialmente los comerciales) y propagación mediante injertos (SF) y uso como portainjerto (P). Espacio: Ámbito peridoméstico $(A P)$, huerta $(H)$, rozado $(R)$, campo $(C)$, capuera $(C P)$ y monte $(M)$. 


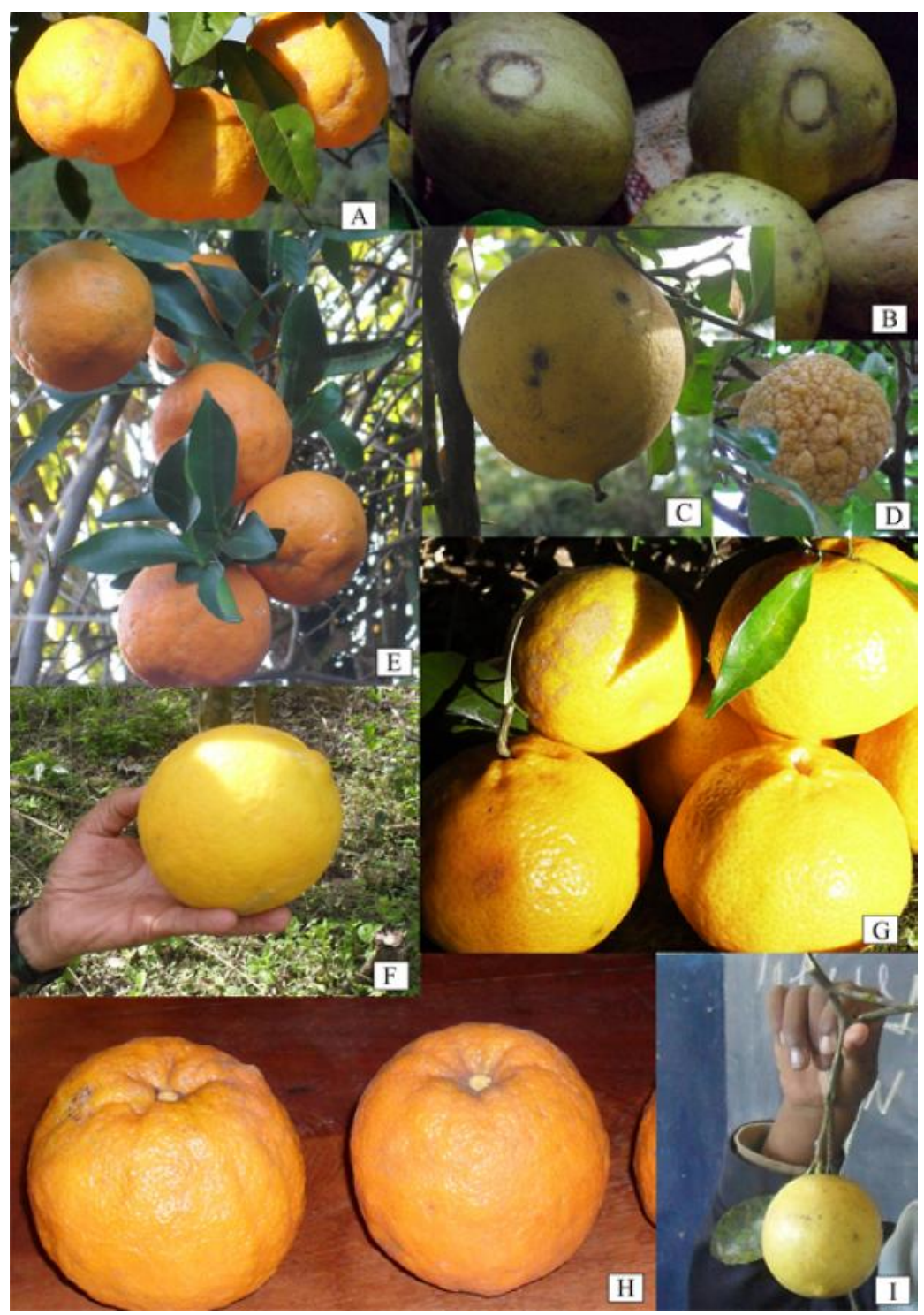

Figura 3. Ejemplos de algunas de las etnoespecies de cítricos observados A: limón mandarina; B: cidra; C: limón lima; D: limón cidra; E: mandarina de injerto; F: limón real; G: mandarina común; H: apepú; I: lima.

cientes a 2 grupos de etnovariedades reconocidas localmente según diversos atributos (Lambaré y Pochettino 2012) (Tabla 2 y Figura 4) que difieren de los caracteres buscados por el productor y de mercado. De esta manera, aunque en los últimos años se han registrado ingresos de variedades comerciales, a diferencia de lo que ocurre en el NEA con los citrus, en esta zona de estudio no se ha establecido un cultivo industrial de duraznos, incluso las variedades comerciales introducidas no significaron una instancia de diversificación o incorporación de germoplasma novedoso a los cultivos locales. En el noroeste, en el presente, en las yungas el cultivo de los duraznos se observa en espacios peridomésticos; se emplean para consumo familiar y por lo general son unas pocas plantas. En la región de los valles secos en cambio se ha observado el cultivo de duraznos en parcelas mayores (0,5-2 ha) denominadas rastrojos (Troncoso 2003) y se encuentran a nivel o presentan una pendiente moderada. En ella se siembran distintas variedades de duraznos acompañado de otros frutales como peras (Pyrus communis L.), manzanas (Malus domestica Borkh), albarillos (Prunus armeniaca L.) y membrillos (Cydonia oblonga Mill.), así como cayotes (Cucurbita ficifolia Bouché) y maíz (Zea mays L.). 
Tabla 2. Etnovariedades de durazno propias de la Quebrada de Humahuaca

\begin{tabular}{|c|c|c|c|c|}
\hline Grupo de etnovariedades & Etnovariedad & Manejo Local & Estado & Espacio \\
\hline \multirow[t]{2}{*}{$\begin{array}{l}\text { Durazno común (adherencia } \\
\text { del endocarpo y mesocarpo) }\end{array}$} & $\begin{array}{l}\text { Amarillo entero } \\
\text { Amarillo corazón } \\
\text { rojo } \\
\text { Blanco } \\
\text { Rosado } \\
\text { Durazno Jorge } \\
\text { (=cholo cholito) }\end{array}$ & $\begin{array}{l}\text { Selección de semillas } \\
\text { provenientes de } \\
\text { cosechas anteriores, } \\
\text { las cuales son defini- } \\
\text { das por caracteres } \\
\text { deseados por los } \\
\text { pobladores (productor, } \\
\text { algún familiar o amigo) } \\
\text { Experimentación en la } \\
\text { propagación vegetativa } \\
\text { a partir de injertos, } \\
\text { usando distintos pie } \\
\text { de otras variedades de } \\
\text { duraznos (con menor } \\
\text { frecuencia) }\end{array}$ & Cultivado & Rastrojo \\
\hline & $\begin{array}{l}\text { Durazno alancate } \\
\text { (=olancate) }\end{array}$ & & & \\
\hline $\begin{array}{l}\text { Durazno prisco (=frisco, } \\
\text { de partir) (ausencia de } \\
\text { adherencia del endocarpo } \\
\text { y mesocarpo) }\end{array}$ & $\begin{array}{l}\text { Amarillo } \\
\text { Blanco } \\
\text { Rosado }\end{array}$ & & & \\
\hline
\end{tabular}

En los terrenos de cultivos estas especies se encuentran por sectores, sin embargo, es posible observar plantaciones asociadas con cultivos anuales intercalados. El cuidado de este espacio agrícola y principalmente del cultivo de durazno es una actividad que desarrollan las mujeres. Las actividades agrícolas comienzan en el mes de agosto, siendo la poda y limpieza del terreno los primeros pasos a seguir por los pobladores. Pasadas las últimas lluvias de verano los primero duraznos comenzaran a madurar. La época de cosecha comienza entre los meses de marzoabril, la fruta que se obtiene de esta etapa es destina al consumo y para la venta, aquellos duraznos que no llegan a ser cosechados, que quedan en el terreno ya maduros serán destinados para la elaboración de «pelones», la elaboración de ello permite a las familias conservar por un período largo la fruta en estado deshidratado. La propagación de este cultivo se realiza por semilla y por injerto, esta última forma de conservación del germoplasma puede realizarse de dos manera; la primera es hacer injertos por púas, esta forma recuerdan algunos pobladores que se la enseñaban en la escuela. La segunda forma de propagación es de yema, esta forma los productores aprendieron en capacitaciones. Se pudo establecer que la obtención de semillas, que permitan la regeneración continua de los árboles de duraznos en los rastrojos, es a partir de semillas seleccionadas de cultivos anteriores, en menor medida de otros familiares y de la compra en mercados o ferias.

Esta permanencia se traduce también en los usos alimenticios y medicinales que tienen estas plantas. Se constató que algunos pobladores de los valles secos usan el jugo de los duraznos deshidratados («pelones») hervidos con azúcar («compota») para tratar afecciones relacionadas con los riñones (Lambaré y Pochettino 2012, Stampella et al.2013b). En la zona de los valles orientales, los pobladores cultivan duraznos en el piso intermedio de las Yungas. Las referencias establecen que la decocción realizada con flores secas y semillas molidas son empleadas para tratar afecciones relacionadas con los intestinos (diarreas, meteorismo, inflamación intestinal). Se toma hasta tres veces por día y si persiste el malestar se repite dos días consecutivos. Asimismo los cogollos son empleados en medicina templaria, son macerados en vinagre, para eliminar el calor del cuerpo se lo friccionan en el. Asimismo para el «chuscho» (fiebre muy alta con sudoraciones) se prepara una infusión, la que debe ser tomada 3 veces (Hilgert 


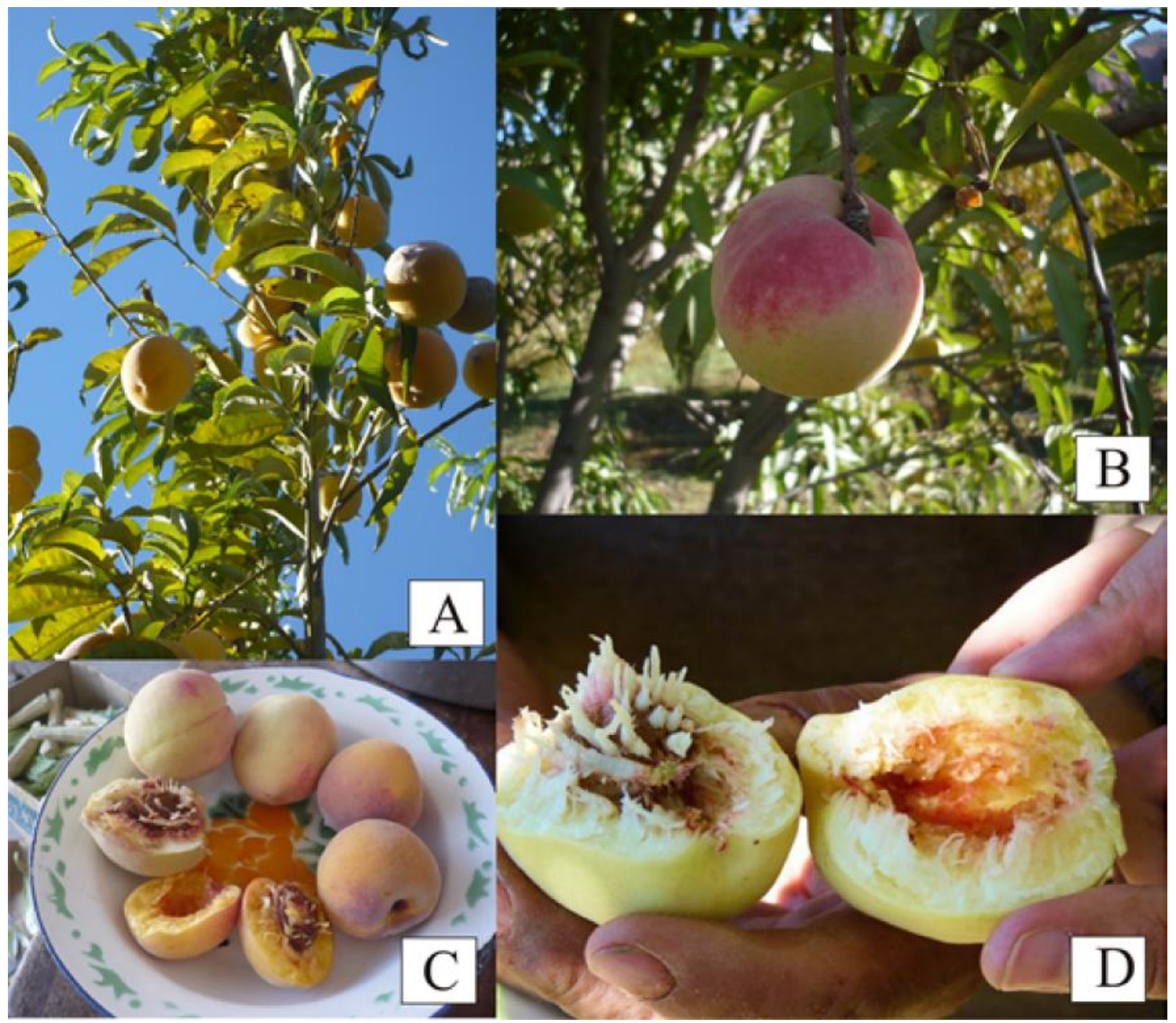

Figura 4. Ejemplos de algunas de las etnoespecies de duraznos observadas. A: común amarillo; B: común rosado; C: frisco amarillo; D: frisco blanco.

2001). La parte carnosa de este frutal junto con el de manzana se los mezcla y muelen para ser empleados como elemento aglutinante en la elaboración de «yista»: preparados sólidos de origen vegetal que se utilizan junto con la «coca» (Hilgert 2000, Hilgert et al.2001).

\section{Conclusiones}

Se han identificado 9 etnoespecies (divididas en dos grupos de etnovariedades) de duraznos y 8 etnoespecies (que incluyen 27 etnovariedades) de cítricos presentes en las áreas mencionadas, las cuales son expresivas de la diversidad biocultural local. Los ejemplos planteados permiten inferir que estas especies se han incorporado en la visión local como propias, y que a través de procesos locales de selec- ción cultural han resultado en poblaciones de especies útiles que conforman un paisaje típico de las zonas de estudio, como resultado de la domesticación del ambiente incluso en un plazo corto como el que representan estos frutales introducidos a partir de la colonización española. La diversidad biológica de frutales presente se explica por las introducciones en épocas pasadas, así como por los procesos biológicos de diversificación que ocurren espontáneamente al igual que los procesos culturales de selección de dicha diversidad y fijación por métodos varios.

Las características de las poblaciones nativas y de las corrientes colonizadoras conformaron paisajes culturales con particularidades propias, las cuales se reflejan en las especies vegetales y los usos que prestan. Dentro de las especies frutales introducidas en el norte de Argentina, los «duraznos», contaban 
con una larga historia de uso en Europa (aunque su origen fuera asiático o en zonas limítrofes entre ambos hemicontinentes). Al momento de la conquista y la colonia, a medida que ocurre su introducción, se reproduce lo que se había dado en Europa, donde se incorporaron como alimento de gran aprecio, con pocas aplicaciones medicinales. En tanto que los citrus, de corta historia en común con los europeos, son altamente valorados no sólo como comestibles sino también como medicinales. En el noroeste, las corrientes colonizadoras introdujeron elementos cultivados en España que fueron ingresados desde Perú. Desde el punto de vista ecológico la Quebrada es receptora de duraznos, manzanas (Malus domestica Borkh), peras (Pyrus communis L.) y membrillos (Cydonia oblonga Mill.). En consecuencia, tanto por razones culturales como ambientales, los pueblos agrícolas adoptaron rápidamente estos elementos y los cultivaron. Pero, en este proceso se fueron seleccionando variedades que respondían a los valores locales, así como aquellas que toleraban mejor el clima de la nueva tierra. De este modo se configuraron variedades reconocidas como definitorias de un entorno agrícola, los «duraznos de la Quebrada» (en referencia a la Quebrada de Humahuaca) y considerados como identitarios por los pobladores. Estos duraznos se mantienen sólo bajo cultivo, y no se han encontrado poblaciones naturales (aparecen en forma excepcional algunos ejemplares espontáneos en los alrededores de los rastrojos). Sin embargo, constituyen un elemento conspicuo en el paisaje local, entendido éste como el espacio interpretado por los pobladores.

En el NEA en cambio, la introducción de los cítricos resultó de la confluencia de las corrientes colonizadoras española corriente del Río de la PlataAsunción y la brasileña (Portugal + África + India + SE asiático) sobre poblaciones que derivaban su economía no sólo de la agricultura sino a través de actividades extractivas en las cuales el monte (la selva) constituía la garantía de realización. Estos cítricos, a través de la agencia de los jesuitas, se constituyen en un elemento conspicuo en el paisaje local, deviniendo con el tiempo en cultivos característicos de la zona. Asimismo, algunas de estas especies se naturalizan y forman parte de la flora espontánea de distintos ambientes, ya sean montes secundarios donde aparecen en forma espontánea así como en capueras a modo de relictos de antiguas plantaciones. En ambos casos son reconocidos por los pobladores como originarios de la zona.

En ambos casos, tanto en el NEA como el NOA, en forma paralela al establecimiento de estos cultivos como recurso agrícola y económico, se fueron desarrollando usos diversos como los terapéuticos mencionados a lo largo del texto, en muchos casos novedosos con respecto a los que registran en otras partes del mundo, resultantes de la experimentación local.

A pesar de las diferencias, los ejemplos planteados permiten comprender los procesos de apropiación local de las especies introducidas. La decisión de incorporar elementos ajenos, debe entenderse en el marco de las cosmovisiones de estos grupos nativos de distintas zonas de América. Grupos que están atravesando por un momento de fuertes transformaciones, pero sin resignar protagonismo en la tomas de decisiones que contribuyen a la reproducción cultural. En efecto, participan activamente, ya sea rechazando, incorporando, resignificando o abandonando costumbres, objetos y productos dentro de la incesante dinámica social e histórica. Dentro de ese marco cultural, la apropiación de los «duraznos» y los «cítricos», convierte a estos frutales originariamente foráneos, en elementos identitarios, que contribuyen a la definición de sus comunidades y escenarios de la vida cotidiana. Dado que esos ambientes pueden experimentar modificaciones, y suele variar su materialidad a lo largo del tiempo, estas plantas de introducción relativamente reciente, y con registro escrito, permiten al investigador comprender y diseñar la domesticación del paisaje, en cuanto resultado multidimensional del entorno físico, significativo y social (Molano Barrero 1997 en Vitri 2007, Seeland 1997). En ese contexto, proponemos que este tipo de recursos foráneos, naturalizados primero y resignificados luego, sean considerados como especies antropizadas y, con ello, se analicen como parte del paisaje y no como elemento generador de alteraciones en el mismo.

\section{Agradecimientos}

Agradecemos especialmente a los habitantes del NOA y NEA por compartir sus conocimientos, tiempo y gentileza. Al Laboratorio de Botánica Sistemáti- 
ca y Etnobotánica (LABOCyE) FCA, UNJu, Laboratorio de Etnobotánica y Botánica Aplicada (LEBA) FCNyM, UNLP, y del Instituto de Biología Subtropical (IBS) FacFor, UNaM y CONICET por el apoyo logístico y a UNaM, UNLP y CONICET por el financiamiento de la investigación.

\section{Literatura citada}

Acosta J de. 1590. Historia natural y moral de las Indias. Sevilla: Impreso en Casa de Juan León; 411 p.

Albeck MA. 1994. Taller de Costa a Selva. Producción e Intercambio entre los pueblos agroalfareros de los Andes Centro Sur. Tilcara: Instituto Interdisciplinario Tilcara. pp. 177-197.

Albuquerque UP, Paiva de Lucena RF, Cruz da Cunha LVF. 2010. Métodos e técnicas na pesquisa etnobiológica y etnoecológica. Recife: Nuppea. pp. 156-70.

Ambrosetti JB. 2008a [1892-1894]. Primer y segundo viaje a Misiones por Juan Bautista Ambrosetti. Comentado por JC Chebez y B Gasparri. Buenos Aires: Editorial Albatros, Fundación de Historia Natural Félix de Azara; 319 pp.

Ambrosetti JB. 2008b [1896]. Tercer viaje a Misiones por Juan Bautista Ambrosetti. Comentado por JC Chebez y B Gasparri. On line. Buenos Aires: Editorial Albatros, Fundación de Historia Natural Félix de Azara. 171 pp. Acceso 16 de julio de 2013, en: http://www.losquesevan. com/libro-tercer-viaje-a-misiones-por-juan-bautistaambrosetti.516c

Azara F. de. 1847 [1806?]. Descripción é historia del Paraguay y del Río de la Plata. Tomo I.

Báez JR. 1947. La primera colonia agrohispana en el Tucumán (Siglo XVI). Rev Arg Agronom 14 (2): 85-93.

Báez JR. 1949. Breves apuntes sobre la migración de las plantas agrícolas Euro-Indianas en el momento del descubrimiento. Lilloa. 18: 311-60.

Balée W. 1998. Advances in historical ecology. New York: Columbia University Press; 429 pp.

Bartolomé MA. 1978. Parientes de la selva. Los Guaraníes Mbya de la Argentina. Vol. 72. Asunción: Centro de Estudios Antropológicos de la Universidad Católica. Biblioteca Paraguaya de Antropología. 463 pp.

Bartolomé LJ, Schiavoni G. 2008. Desarrollo y estudios rurales en Misiones. Buenos Aires: Ediciones CICCUS; 326 pp.

Bernard RH. 2000. Social research methods. Qualitative and quantitative approaches. California: Thousand Oaks, Sage Publications, Inc. 659 pp.

Brabo FJ. 1872. Colección de documentos relaticos á la expulsión de los jesuitas de la República Argentina y del Paraguay. Madrid: Establecimiento Tipográfico de JM Pérez. 404 pp.

Burger P, Terral JF, Ruas MP, Ivorra S, Picq S. 2011. Assessing past agrobiodiversity of Prunus avium L. (Rosaceae): a morphometric approach focussed on the stones from the archaeological site Hôtel-Dieu $\left(16^{\text {th }}\right.$ century, Tours, France). Veget Hist Archaeobotan. 20 (5): 447-58.
Burmeister C. 1899. Memoria sobre el territorio de Misiones. Buenos Aires: Ministerio de Agricultura de la República Argentina. Impr. Litogr y Encuad De J. Peuser. 77 pp.

Cabeza de Vaca AN. 1947. Naufragios y comentarios. $3^{\mathrm{a}}$ ed. Buenos Aires: Ed. Espasa-Calpe; 262 pp.

Cabrera AL. 1976. Regiones fitogeográficas argentinas. Buenos Aires: Enciclopedia de Agricultura y Jardinería 2.

Cadogan L. 1957. Apuntes de medicina popular Guaireña. Asunción: Centros de Estudios Antropológicos del Paraguay.

Cadogan L. 1969. Cadogan, según Cadogan. Entrevista Diario La Tribuna, 9 de febrero de 1969. Acceso 13 de marzo de 2013, en: http://www.portalguarani.com/obras_autores_ detalles.php?id_obras $=17830$.

Capparelli A, Raffino RA. 1997. Arqueoetnobotánica de El Shincal I: tallos finos, frutos y semillas. Tawantinsuyu. 3: 40-57.

Capparelli A, Lema V, Giovannetti M, Raffino R. 2005. The introduction of old world crops (wheat, barley and peach) in Andean Argentina during the 16th century AD: archaeobotanical and ethnohistorical evidence. Veget Hist Archaeobot. 14: 472-84.

Capparelli A, Hilgert N, Ladio A, Lema V, Llano C, Molares S. 2011. Paisajes culturales de Argentina: pasado y presente desde las perspectivas etnobotánicas y paleobotánicas. Rev Asoc Arg Ecol Pais. 2 (2): 67-79.

Carbonell R (SJ). 1992. Estrategias de desarrollo rural en los pueblos guaraníes (1609-176). Barcelona: Antoni Bosch, Sociedad Estatal Quinto Centenario, Instituto de Estudios Fiscales \& Instituto de Cooperación Iberoamericana. 512 pp.

Cardiel J (SJ). 1994 [1771]. Breve relación de las misiones del Paraguay. Prólogo de E. Maeder. Buenos Aires: Secretaría de Cultura de la Nación y Ed. Teoria. 188 pp.

Casas B de las. 1875. Historia de las Indias. Tomo II. Madrid: Edición del Marqués de la Fuensanta del Valle y D. José Sancho Rayon, Imprenta de Miguel Ginesta. 520 pp.

Chase-Sardi M. 1989. El tekoha. Su organización social y los efectos negativos de la deforestación entre los Mbyáguaraní. Supl Antropol 24 (2): 33-41.

Chebez C. 2005. Guía de las reservas naturales de la Argentina. Nordeste. Buenos Aires: Editorial Albatros. 288 p.

Citrus Pages. Acceso 18 de marzo de 2013. URL disponible en: http://users.kymp.net/citruspages/home.html

Cobo B (SJ). 1890-1892. Historia del Nuevo Mundo. Sevilla: Sociedad de Bibliófilos Andaluces.

Commelyn S. 1683. The Belgick, or Netherlandish Hesperides. En línea (Acceso 20 de mayo de 2013). URL http:// archive.org/details/mobot31753000819604

Compañía Tabacalera de Misiones Ltda. Acceso 18 de marzo de 2013, en: http://www.cooptabmis.com/citrusespanol.html

Depypere L, Chaerle P, Vander Mijnsbrugge K, Goetghebeur P. 2007. Stony endocarp dimension and shape variation in Prunus section Prunus. Ann Bot. 100: 1585-97.

Díaz de Guzmán R. 2000. La Argentina. Madrid: Ed. DASTIN Historia. $267 \mathrm{pp}$.

Dobrizhoffer M. 1967. Historia de los Abipones. I. Resistencia: Facultad de Humanidades. Universidad Nacional del 
Nordeste.

Farberman J, Boixadós R. 2006. Sociedades indígenas y encomienda en el Tucumán Colonial. Un análisis comparado de la visita de Luján de Vargas. Rev Indias. 47 (238): 601-28.

Ferrari JB (SJ). Flora seu de florum cultura. Lib. IV. (En línea) 1646 (Acceso 20 de mayo de 2013) URL http:// archive.org/details/mobot31753000543642

Gallero MC, Krautstofl EM. 2009. Proceso de poblamiento y migraciones en la provincia de Misiones, Argentina (18811970). Avá. 16: 245-64.

Gálvez L. 1995. Guaraníes y jesuitas. De la Tierra sin Mal al Paraíso. Buenos Aires: Editorial Sudamericana. 412 pp.

Gambón V. 1904. A través de las misiones guaraníticas. Buenos Aires: Ángel Estrada y Cía. 139 p.

García Paris J. 1991. Intercambio y difusión de plantas de consumo entre el Nuevo y el Viejo mundo. Madrid: Servicio de Extensión Agraria. Ministerio de Agricultura, Pesca y Alimentación. 293 p.

Gentile Lafaille ME. 2012. Geografía y política. La gobernación de Tucumán 1582, según la relación de Pedro Sotelo del Narváez. Anua Jurid Econ Escurial. 45: 581-608.

Giovannetti M. 2005. La conquista del noroeste Argentino y los cultivos europeos. Front Hist. 10: 253-83.

Giovannetti M, Lema V. 2005. Cultivos introducidos por los europeos en el Shinkal de Quimivil: La presencia de los hispanos en la supervivencia ritual. En: Cetti A, Re A, Rindel D y Valeri P (Coord.). Entre pasado y presente. Trabajo de las VI Jornadas de jóvenes investigadores en ciencias antropológicas. Buenos Aires: Instituto Nacional de Antropología y Pensamiento Latinoamericano. 410-29 pp.

Grant V. 1989. Especiación vegetal. México: Editor Limusa SA. $200 \mathrm{pp}$.

Hernández Bermejo JE, Lora González A. 1996. La documentación histórica y bibliográfica como fuente de información y evidencia etnobotánica. Monogr Jard Bot Cord. 3: 39-50.

Hieronymus J. 1882. Plantae diaphoricae florae argentinae. Bol Acad Nal Cien Cord. 4 (3): 199-598.

Hilgert NI. 2000. Especies vegetales empleadas en la insalivación de hojas de «coca» (Erythroxylum coca var. coca, Erythroxylaceae). Darwiniana. 38 (3-4): 241-52.

Hilgert NI. 2001. Plants used in home medicine in the Zenta River basin, Northwest Argentina. J Ethnopharmacol. 76: 11-34.

Hilgert NI, Reyes S, Schmeda-Hirschmann G. 2001. Alkaline substances used with coca (Erythroxylum coca, Erythroxylaceae) leaf insalivation in northwestern Argentina. Econ Bot. 55 (2): 325-9.

Hilgert NI, Gil GE. 2005. Traditional andean agriculture and changing processes in the Zenta River Basin, Salta, Northwestern Argentina. Darwiniana. 43 (1-4): 30-43.

Holmberg EL. 1887. Viaje a Misiones. Bol Acad Nal Cien Cord. 10: 252-88.

Hurrell JA, Ulibarri EA, Delucchi G, Pochettino ML. 2010. Frutas frescas, secas y preservadas. Buenos Aires: Editorial LOLA. 301 p.
IBODA. 2013. Instituto de Botánica Darwinion. Base de Datos. Flora del Conosur. Acceso 12 de marzo de 2013, en: http://www2.darwin.edu.ar/Proyectos/FloraArgentina/ FA.asp

Karasik G. 1984. Intercambio tradicional en la Puna Jujeña. Runa. 14: 51-91.

Keller HA, Delucchi G, Romero HF. 2011 Camellia sinensis (Theaceae) en la Argentina: Naturalización y usos locales. Bol Soc Arg Bot 46 (1-2): 145-50.

Kumamoto J, Scora RW, Lawton HW, Klerx WA. 1987. Mystery of the Forbidden Fruit: Historical Epilogue on the Origin of the Grapefruit, Citrus paradisi (Rutaceae). Econ Bot. 41 (1): 97-107.

Lambaré DA, Pochettino ML. 2012. Diversidad local y prácticas agrícolas asociadas al cultivo tradicional de duraznos Prunus persica (ROSACEAE), en el Noroeste de Argentina. Darwiniana. 50 (2): 174-86.

Lema VS. 2009. Domesticación vegetal y grado de dependencia ser humano- planta en el desarrollo cultural Prehispánico del noroeste argentino. (Tesis doctoral). Buenos Aires, La Plata: Facultad de Ciencias Naturales y Museo, Universidad Nacional de La Plata. 762 pp.

Levillier R. 1939. Historia de la nación Argentina desde los orígenes hasta la organización definitiva en 1862. Vol II. El Ateneo. Buenos Aires.

Lista R. 1883. El territorio de las Misiones. Buenos Aires: Imprenta «La Universidad» de J. N. Klingelfuss. 114 p.

Lizárraga R de. 2002 (1607?). Descripción del Perú, Tucumán, Río de La Plata y Chile. Madrid: Editorial DASTIN Historia. 475 p.

López de Gómara F. 1922. Historia general de las Indias. Cap. 2. Madrid: Calpe. 265 pp.

Lorandi AM. 1988. El servicio personal como agente de desestructuración en el Tucumán colonial. Rev Andina. 6 (1): 135-73.

Martínez-Crovetto R. 1963. Esquema fitogeográfico de la provincia de Misiones (República Argentina). Bonplandia. 1 (3): 171-223.

Mörner M. 1985. Actividades políticas y económicas de los jesuitas en el Río de la Plata. Buenos Aires: Ed. Hyspamerica. $261 \mathrm{p}$.

Navarro G, Maldonado M.2002. Geografía ecológica de Bolivia, vegetación y ambientes. Santa Cruz: Editorial Centro de Ecología Difusión Simón I. Patiño. 719 pp.

Ochoa J, Ladio A. 2011. Pasado y presente del uso de plantas silvestres con órganos de almacenamiento subterráneos comestibles en la Patagonia. Bonplandia. 20 (2): 265-84.

Palacios J. 1978. Citricultura Moderna. Buenos Aires: Ed. Hemisferio Sur. 409 p.

Palomeque S. 2000. El mundo indígena (siglos XVI-XVIII). En: Tandeter, E. (dir.). Nueva Historia Argentina. La sociedad colonial. Buenos Aires: Ed. Sudamericana.pp. 87-144.

Paucke F (SJ). 1944. Hacia allá y para acá (Una estada entre los indios mocobíes 1749-1767). Traducción castellana por E. Wernicke. Tomo III, segunda parte. Tucumán: Universidad Nacional del Tucumán.

Puente, Olea M de la. 1900. Los trabajos geográficos de la Casa de la Contratación. Sevilla: Escuela Tipográfica y 
Librería Salesianas. pp. 98-105.

Raffino RA. 1999. La Argentina aborigen. Conquista y colonización. Nueva historia de la Nación Argentina. Tomo I. Editorial Planeta.

Raffino RA, Gobbo JD, Iácona A. 2006. De Potosí y Tarija a la frontera Chiriguana. Folia Hist Nordeste. 16: 83-129.

Ramón-Laca L. 2003. The introduction of cultivated citrus to Europe via northern Africa and the Iberian Peninsula. Econ Bot. 57 (4): 502-14.

Richardson DM, Pysek P, Rejmanek M, Barbour MC, Dane Panetta F, West CJ. 2000. Naturalization and invasion of alien plants: concepts and definitions. Divers Distrib. 6 : 93-107.

Ruíz de Montoya A. 1892. Conquista espiritual hecha por los religiosos de la Compañía de Jesús en las provincias del Paraguay, Paraná, Uruguay y Tape. Bilbao: Imprenta del Corazón de Jesús.

Sánchez Labrador J. 1910. El Paraguay católico. Homenaje de la UNLP al XVII Congreso Internacional de los Americanistas en su reunión de Buenos Aires, en mayo 16 a 21 de 1910. Buenos Aires: Imprenta de Coni Hnos.

Scarpa GF, Arenas P. 1996. Especias y colorantes en la cocina tradicional de la Puna jujeña (Argentina). Candollea. 51: 483-514.

Schaden E. 1998. Aspectos fundamentales de la cultura Guaraní. Asunción Universidad Católica «NS de la Asunción». Centro de Estudios Antropológicos (CEADUC). Biblioteca Paraguaya de Antropología.

Schiavoni G. 1995. Organización doméstica y apropiación de tierras fiscales en la Provincia de Misiones (Argentina). Desarrollo Económico 34: 595-608.

Schiavoni G. 1998. Colonos y ocupantes: parentesco, reciprocidad y diferenciación social en la frontera agraria de Misiones. Posadas (Misiones): Editorial Universidad Nacional de Misiones.

Schmidl U. 1944. Derroteo y viaje a España y las Indias. Buenos Aires: Colección Austral. Espasa-Calpe.

Seeland K. (ed.). 1997. Nature is culture: indigenous knowledge and sociocultural aspects of trees and forests in nonEuropean cultures. London: Intermediate Technology Publications Ltd. $152 \mathrm{pp}$.

Seo MN, Xifreda C. 2008. Rutaceae. En: Anton AM, Zuloaga FO (Eds.). Flora Fanerog Arg. 106: 1-22.

Sepp A (SJ). 1971 [1696]. Relación de viaje a las Misiones Jesuíticas. Edición crítica de W. Hoffmann. Tomo I. Buenos Aires: Ed. EUDEBA.

Sica G. 2005. Del pucará al pueblo de indios. El proceso de construcción de la sociedad indígena colonial en Jujuy, Argentina, siglo XVII. Tesis doctoral. Sevilla: Universidad de Sevilla.
Sica G. 2010. Del tráfico caravanero a la arriería colonial indígena en Jujuy. Siglos XVII y XVIII. Rev Transp Territ. 3: 2339. Buenos Aires: Universidad de Buenos Aires.

Sica G, Bovi MT, Mallagray L. 2010. La quebrada de Humahuaca: de la colonia a la actualidad. En: Jujuy en la historia de la colonia al siglo XX. Teruel A, Lagos M (directores). Jujuy: Universidad Nacional de Jujuy. 351-72 pp.

Stampella PC, Delucchi G, Pochettino ML. 2013a. Naturalización e identidad del «limón mandarina», Citrus x taitensis (Rutaceae, Aurantioideae) en la Argentina. Bol Soc Arg Bot. 48 (1): 161-9.

Stampella PC, Lambaré DA, Hilgert NI, Pochettino ML. 2013b. What the iberic conquest bequeated to us: the fruit trees introduced in argentine subtropic, their history and importance in present traditional medicine. EvidenceBased Complementary and Alternative Medicine. Article ID $868394,17 \mathrm{p}$.

Storni JS. 1944. Hortus guaranenesis. Flora. Tucumán: Universidad Nacional de Tucumán. 268 pp.

Susnik B. 1979-1980. Los aborígenes del Paraguay: Tomo II. Etnohistoria de los Guaranies: época colonial. Asunción: Museo Etnográfico «A. Barbero», Escuela Técnica Salesiana. 332 pp.

Torres GF, Bianchetti MC, Santoni ME. 1985. La dieta de los campesinos del Valle Calchaquí y de la Puna y sus determinantes culturales. Kallawaya. Serie Monográfica $\mathrm{n}^{\circ} 1.46 \mathrm{pp}$

Troncoso C. 2003. El diseño de las estrategias de vida de los campesinos en Juella. En: Reboratti C (Ed.). La Quebrada. Geografía, Historia y Ecología de la Quebrada de Humahuaca. Buenos Aires: Editorial La Colmena; 139$60 \mathrm{pp}$.

Vázquez de Espinosa A. 1948. Compendio y descripción de las indias occidentales. Transcrito del manuscrito original por Charles Upson Clark. Washington: Smithsonian Institution. $801 \mathrm{pp}$.

Vitri C. 2007. La ruta de Diego de Almagro en el territorio argentino: un aporte desde la perspectiva de los caminos prehispánicos». Rev Esc Hist. 6 (1).

Volkamer JC. Hesperidum Norimbergensium sive de malorum, citreorum, limonum, aurantiurumque cultura et usu. Libri IIII. (En línea). 1708-1714 (Acceso 20 de mayo de 2013) URL http://archive.org/details/mobot31753000819604

Webber H. 1943. History and development of the Citrus industry. En Webber H y Batchelor L (Eds.). The Citrus industry. Berkeley and Los Angeles: University of California Press. pp. 1-40.

Zhang X, Mabberley DJ. 2008. Citrus. En: Wu ZY, Raven PH y Hong DY. Flora of China. China and Missouri Botanical Garden Press. pp. 90-96. 